\title{
O MAGMATISMO SHOSHONÍTICO PIRACAIA, SP (SE BRASIL)
}

\author{
E.Wernick ${ }^{1}$, A.C.Artur ${ }^{1}$, F.C.Fahl ${ }^{1}$, P.K.Hörmann ${ }^{2}$, K.Weber-Diefenbach ${ }^{3}$
}

O magmatismo shoshonítico Piracaia é uma das quatro manifestações magmáticas reunidas no complexo plurisserial Socorro (SP/MG) e encontra sua maior manifestação no maciço homônimo de cerca de $30 \mathrm{~km}^{2}$, leste do Estado de São Paulo. Entre suas principais características cabe destacar:

- A Suíte Piracaia reúne (quartzo) monzogabros, monzodioritos, monzonitos, ao lado de raros sienitos e granitos cuja mineralogia compreende variáveis combinações de feldspato alcalino, plagioclásio, clino- e ortopiroxênios, hornblenda, biotita e quartzo;

- O magmatismo é do tipo alto potássio (Fig. 1) e a variação no teor dos álcalis é controlado pelo sódio (Fig. 2);

- O magmatismo é alcalino transicional (nefelina na norma, mas ausente na moda) e sua evolução acompanha o plano definido pela seqüência hawaitos-mugearitosbenmoreitos-traquitos. A partir do fracionamento mais intenso é gerado um magma residual que via quartzo sienitos evolui em direção ao mínimo granítico (Fig. 3);

shoshoniticas (Figs. 4 e 5);

- A evolução do magmatismo segue a tendência evolutiva de outras suítes

- A relação inicial $\mathrm{K} / \mathrm{Rb}$ sugere um magma gerado a partir de um manto litosférico enriquecido possivelmente pela gênese do magmatismo cálcio-alcalino Socorro I, do complexo plurisserial homônimo, e isócrono à convergência entre as placas São Francisco e Paraná (Fig. 6);

$8 \mathrm{C})$;

- O fracionamento magmático ocorreu sob condições de alta pressão (Fig. 7);

- Do fracionamento de felspatos resultam rochas cumuláticas (Figs. 8A, 8B e

- O magmatismo caracteriza-se por elevados teores em gadolínio (Fig. 8D);

- O caráter intraplaca do magmatismo é demonstrado por várias relações entre elementos traços (Figs. 9 e 10).

\section{Referências Bibliográficas}

ARTUR, A.C.; EBERT, H.D.; WERNICK, E. (1991) Magmatismo e tectônica no Complexo Socorro (SP/MG). In: SIMPÓSIO DE GEOLOGIA DO SUDESTE, 2., São Paulo, 1991. Atas. São Paulo, SBG/SP-RJ. p.105-112.

CAMPOS NETO, M.C.; BASEI, M.A.S.; ARTUR, A.C.; SILVA, M.E.; MACHADO, R.; DIAS NETO, C.M.; FRAGOSO-CESAR, A.R.; SOUZA, A.P. (1983) Geologia das Folhas Piracaia e Igaratá. In: JORNADA DA CARTA GEOLÓGICA DO ESTADO DE SÃO PAULO EM 1:50.000, 1., São Paulo, Pró-Minério/IPT. p.55-79.

\footnotetext{
${ }^{1}$ DPM, Instituto de Geociências e Ciências Exatas, Universidade Estadual Paulista.

${ }^{2}$ Mineralogisch-Petrographisches Inst. und Museum, Kiel, Alemanha.

${ }^{3}$ Inst. für Allgemeine und Angewandte Geologie, München, Alemanha.
} 
GOMES, E.P.; PLATEVOET, B. (1994) O complexo ácido-básico de Piracaia-SP: Representação de um magmatismo de afinidade shoshonítica do Ciclo Brasiliano. In: CONGRESSO BRASILEIRO DE GEOLOGIA, 38., Camboriú, 1994. Anais. Camboriú, SBG. v.3, p.32-34.

JANASI, V.A. (1986) Geologia e petrologia do Maciço Monzodiorítico-Monzonítico de Piracaia. São Paulo. 218p. (Dissertação - Mestrado) - Instituto de Geociências, Universidade de São Paulo. 

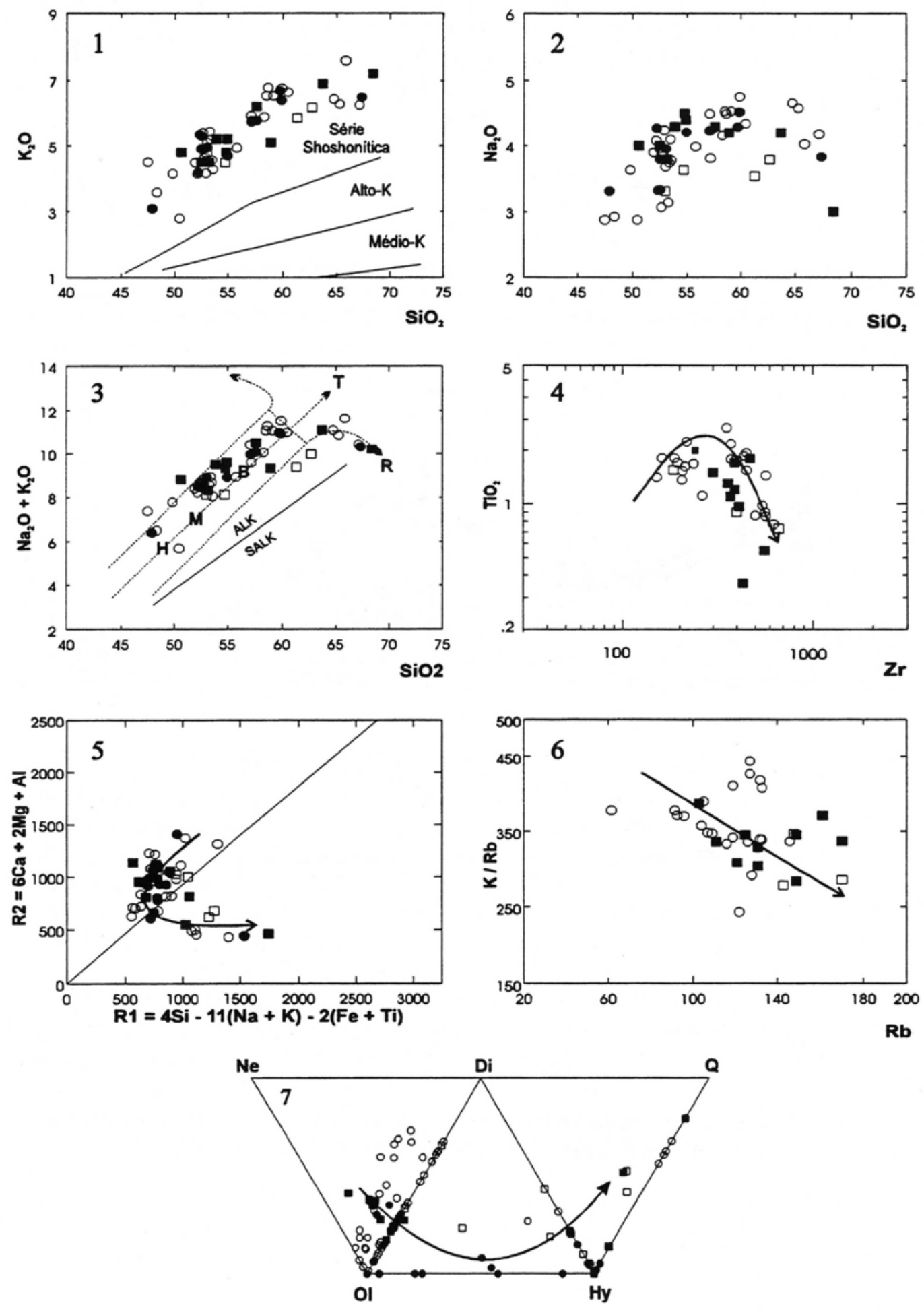

Figuras 1 a 7 - Diagramas mostrando variadas feições geoquímicas do Magmatismo Piracaia ( $\square$ Campos Neto et al., 1983; - Janasi, 1986; ○ Artur et al., 1991 e $\bullet$ Dados Inéditos). 

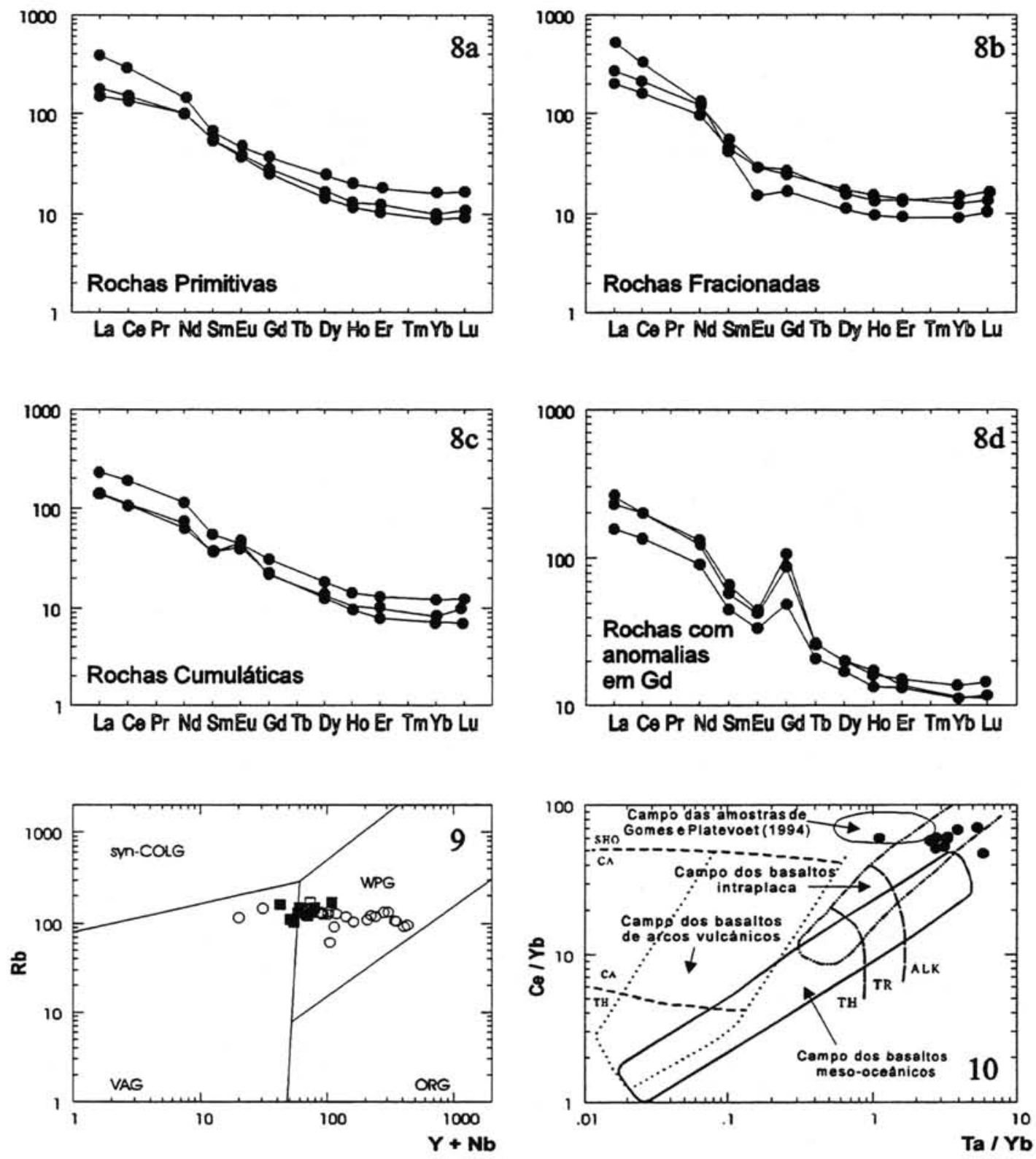

Figuras 8 a 10 - Diagramas mostrando variadas feições geoquímicas do Magmatismo Piracaia $\square$ Campos Neto et al., 1983; - Janasi, 1986; ○ Artur et al., 1991 e • Dados Inéditos). 